and also a mock sun $7^{\circ}$ below it, caused by reflection. The primary and secondary bows caused by the latter as source would occupy exactly the positions indicated in the sketch with the appropriate colour arrangement. As the intensity and definition of the mock sun, good at grazing incidence, would fall off rapidly as the angle increased, only the lower part of the bows would be distinctly visible; this also is suggested in the sketch. The calmness of the sea is not specifically mentioned, but seems to be implied by the other weather conditions stated.

South Farnborough, August $3 \mathrm{r}$.

THEre was observed over the Medway estuary on August I8 (7.I5 p.m., B.S.T.) an extremely brilliant rainbow. In addition to secondary bows concentric with the primary (all less than a semicircle), there was seen a bow of considerable brightness having an arc greater than a semicircle. This "anomalous bow" appeared to be of the same radius as the primary bow, had its colours in the same order (i.e. red outer-

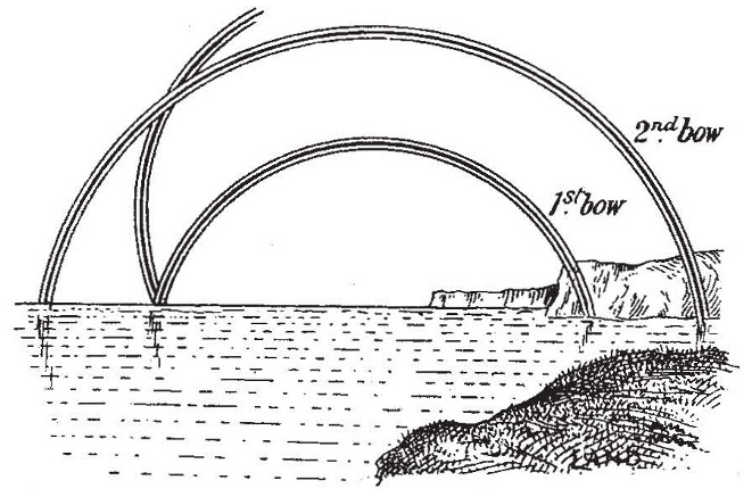

most), and cut the horizon at the same point. It was, in fact, the remainder of the circle of which the primary arc formed a part.

The bow in question presumably originated from the image of the sun reflected in the still water of the foreground, and thus the right-hand end of the primary bow, which stretched overland, was unaccompanied by the eccentric arc. The phenomenon should not be an uncommon one, yet I do not remember to have observed it previously.

Grain, Kent, August i8.

\section{The Sounds of Gunfire.}

THE recent correspondence in the Times referring to the audibility of the reports at great distances induces me to record my experiences here. I have a garage, built of corrugated iron and lined with matchboard. It stands on a concrete base, and the floor is cemented. Its dimensions are $20 \mathrm{ft}$. by io $\mathrm{ft}$., by $\mathrm{I} 5 \mathrm{ft}$. to the ridge. I can hear the sounds of the guns inside the building on days when they are inaudible outside. When audible outside they are considerably accentuated within.

The same thing occurs in the case of a smaller shed, of similar construction, about roo yards away.

A structure of corrugated iron and wood upon a concrete base appears to act as a resonator, collecting and intensifying the sounds. It might be possible to record the sounds on wax cylinders (phonographically) by using an abnormally large megaphonic trumpet directed towards the source of the disturbance.

C. Carus-Wilson.

Strawberry Hill, Middlesex, August 27. NO. 2497 , VOL. IOO]
EDUCATION AND INDUSTRY.

DURING the early part of 1916 the Higher Education Sub-Committee of the Education Committee of the London County Council devoted a great deal of time to interviewing representative employers with the view of obtaining their views on the efficiency of the work done in the various types of educational institutions under its control, and a frank discussion of the relations which should exist between the education given in them and industrial and commercial life. The results of these interviews are summarised in a report recently presented to the Council, which has roused a good deal of comment in the Press, much of it of a very superficial character.

Most of those interviewed were concerned with the distribution and transport of goods or with financial undertakings, but, in addition to these, three groups of employers dealing with what may be said to be the three main London manufacturing industries, engineering, printing, and the chemical trades, were also interviewed.

While the inquiry was generally directed to the possibility of establishing a closer relationship between education and industry than at present exists, the main lines on which it proceeded may be summarised under four heads :-

(I) The methods adopted by business men for recruiting their staffs and the qualifications demanded from applicants.

(2) General defects in the education given by the schools as revealed by the experience of business men.

(3) The possibility of greater assistance being given to employers in making a suitable selection and in providing better material.

(4) The encouragement given by business men to further education of their staffs, and the desirability or otherwise of compulsory further education.

With the criticisms of the representatives of commerce we do not propose to deal beyond remarking that they are largely criticisms of the character and moral produced by the schools, and the most sweeping of them have been shown by the events of the last three years to have very slight foundation. For many of the others the conditions of employment, and particularly of the methods used for selecting employees, which in too many cases pay far too little attention to the selection of the really able and intelligent boy and far too much to personal influence, are much to blame. If a boy in his last years at school feels that someone whom he knows will get him into a post and that it matters very little whether he does his school work well or badly, he has little encouragement to put forth the best that is in him.

The engineering group of trades forms the most important group of manufacturing industries in the London area: few people realise that nearly three-quarters of a million persons are dependent upon it.

The representatives of this group showed a refreshing belief in continued education; they all 